\title{
On international fund construction in South Africa
}

\author{
D.J. Bradfield* \& C.S. Ardington \\ Department of Statistical Sciences, University of Cape Town, Private Bag, Rondebosch, 7700 Republic of South Africa
}

Received June 1997

This article focusses on portfolio construction in markets where legislation restricts investors from investing in international markets. An extended market model is implemented to additionally estimate a component of foreign market risk. In the first part of the article the decomposition of the risk of securities on the Johannesburg Stock Exchange (JSE) is empirically demonstrated. In the second part an automated portfolio construction methodology based on the resulting foreign risk estimates of the model is empirically tested on the JSE. The results confirm there is potential for improving the performance of existing 'international' funds on the JSE using more rigorous quantitative approaches such as the one proposed here.

*Author to whom correspondence should be addressed.

\section{Introduction}

The interest in 'international' or 'global' unit trusts was recently accentuated during March to June 1996 when the assets of international unit trusts grew $46.7 \%$ from R461.8 million to R677.4 million. Although these unit trusts are labelled 'international', local legislation currently permits only $10 \%$ of the funds to be held off-shore via an asset swap. Hence they are not able to share fully in the benefits of International Diversification and consequently attempt to make up the balance ( $90 \%$ ) from local investment. In most instances it is apparent that the local investment that make up this $90 \%$ typically consist of rand hedge shares, that is, shares of companies that operate off-shore or earn revenue off-shore.

Our major aim here is to suggest a quantitative approach to constructing 'international funds' from local shares which to some extent mimic international diversification. We do this by using a model to decompose the risk of 'local' shares into both international and local components. In this way we can identify 'local' shares which are linked to the performance of foreign/international markets. Our next step is to form portfolios of these shares based on the strength of these foreign associations which, it is hoped, will mimic some of the benefits of International Diversification. Although there may be several quantitative approaches we prefer to develop a model which remains within the 'risk-return' framework in which most of Capital Market Theory has evolved. We thus use a model which is an extension of the Market Model (see Bradfield, 1990; and Bradfield, 1993).

The well-known market model, in essence, makes a simple statement concerning the relationship between the returns on a given security and the returns on some market index. The coefficients of the model are of considerable importance to financial analysts and researchers alike. Estimation of the coefficients of the market model requires, inter alia, a series of returns of the given security, and a series of returns on some market index. Usually the market index is constructed from some aggregate of value-weighted securities of the local stock market in question. It is well known that indices constructed in this manner embody movements caused by factors which influence the market as a whole, for example local rates, inflation and the business cycle. It is also likely, however, that movements of overseas markets may have an im- pact on local markets. Consider for example the events of October 1987 (and to a lesser extent October 1989) when the prices of shares listed on the New York Stock Exchange (NYSE) fell dramatically. Prices on all stock exchanges world-wide including Belgium, Frankfurt, London, Paris, Tokyo, Hong Kong, Sydney and the JSE fell in unison. The crash illustrated that events occurring on international markets such as the NYSE can affect stock markets world-wide.

In order to investigate the relationship between international stock markets, the correlation between the NYSE, the London Stock Exchange (LSE), the Tokyo Stock Exchange (TSE) and the JSE was estimated using monthly data from January 1990 to July 1996. The indices used to represent these markets were the Standard and Poor's 500, the Financial Times 100, the Nikkei-Dow and the JSE-Actuaries Overall Index respectively. In addition the correlation between all these markets and a 'world market' was estimated. The Morgan Stanley World Index was used as a proxy for the 'world market'. Table 1 shows the correlation coefficients between the rand returns on these indices.

Table 1 reveals that in all cases the correlation are positive and significant at the $5 \%$ level of significance, confirming that significant relationships between stock markets do exist. The overseas market that has the highest correlation with the JSE is the LSE with a correlation coefficient of 0.336 . The highest correlation of 0.736 in Table 1 is between the Japanese and World market index.

Lessard (1974) conducted a study on the world-wide influences on stock returns. His study included 16 major stock exchanges and a constructed 'world index'. The study examined the international diversification benefits from the viewpoint of the investor with dollars to invest. Lessard (1974) showed

Table 1 Correlation coefficients between rand returns on international markets (January 1990 to July 1996)

\begin{tabular}{lccccc}
\hline & JSE & NYSE & LSE & TSE & WORLD \\
\hline JSE & 1.000 & - & - & - & - \\
NYSE & 0.244 & 1.000 & - & - & - \\
LSE & 0.336 & 0.492 & 1.000 & - & - \\
TSE & 0.265 & 0.375 & 0.445 & 1.000 & - \\
WORLD & 0.192 & 0.572 & 0.631 & 0.736 & 1.000 \\
\hline
\end{tabular}


that, on average, $22 \%$ of the variation in the market indices could be explained by the 'world index'.

Errunza \& Losq (1985) by contrast, have focussed on the debate on whether international markets can be thought of as being either segmented or a perfectly integrated single market. Errunza \& Losq (1985) conducted a study incorporating the US market as well as nine lesser developed countries' (LDCs). On the basis of their results they find tentative support for a mild segmentation hypothesis. This hypothesis assumes that the world's various capital markets do not behave as if they were a perfectly integrated efficient single market, and that this behaviour is caused by the fact that many nonUSA countries restrict free access to capital markets. Various other aspects of the international segmentation-integration issue have been investigated by Solnik (1974), Black (1974), Adler \& Dumas (1975), Grauer et al. (1976), Glenn (1976), Stehle (1977), Stapleton \& Sabrahmanyam (1977) and Stulz (1981a; 1981b).

Most of the above researchers however have focussed on various aspects of asset pricing under conditions of market equilibrium. In this article a more modest objective is pursued, here the focus is concerned primarily with estimating more detailed risk diagnostics for individual securities to identify securities with significant international risk components. In the first section of this article a 'multi-market' model is discussed to estimate a more detailed breakdown of risk than that of the traditional market model. In the second section an empirical study is presented which demonstrates how the model can be used to estimate the risk components across all shares listed on the JSE. In the final section a portfolio construction technique based on the selection of shares with foreign risks is presented and empirically tested on the JSE.

\section{Theoretical discussion}

The notion of risk was originally dealt with in two main conceptual frameworks, the state-preference framework developed by Arrow (1951) and later Debreu (1959), and the mean-variance framework developed by Markowitz (1952). The state-preference framework approach assumes that objects of choice yield payoffs offered in different states of nature. While this framework is useful for investigating theoretical issues, it lacks empirical content due to the difficulty in quantifying all the payoffs offered in different states of nature. The pioneering work of Markowitz (1952; 1959) on portfolio selection in the mean-variance framework however, is the framework that subsequently captured the interest of researchers in the field of financial economics and paved the way for the development of Capital Market Theory in the mean-variance framework. It is within this framework that the variance of a series of returns has been well-entrenched in literature as a measure of total risk. One of the advantages of the model proposed below therefore is that it addresses the notion of risk in the mean-variance framework within which the bulk of Capital Market Theory has evolved.

The model is essentially similar to the model used by Ernunza \& Losq (1985) to investigate the notion of segmentation/integration of world markets and is also similar in spirit to the model used by Lessard $(1973 ;$ 1974), Solnik (1974),
Stehle (1977), Bradfield (1990) and Bradfield (1993) who also investigated the risk across world markets.

The model outlined below does not require any assumption about its process generating returns (see Stehle, 1977). This model, in essence, relates the return of a security listed on some local market to the return on a local market index, plus the return on a world market index. To obtain tractable expressions for the risk components, that is, local market risk, world market risk and unique risk, the vector of local and world market returns are orthogonalized. This amounts to removing the effect of the world index from the returns of the local index. This can be simply achieved by regressing the returns of the local index on the returns of the world index, and using the resultant residuals to represent the local index with the effects of the world index removed.

The model, henceforth referred to as the multi-market model, can be written as

$R_{i 1}=\alpha_{i}+\beta_{i}^{L\left(X \cdot w^{w}\right)} R_{m}^{L(x \cdot w()}+\beta_{i}^{w()} R_{m+1}^{w()}+e_{i n}$

where:

$\mathbf{R}_{\mathrm{it}} \quad=$ the return on share $\mathrm{i}$ at time $\mathrm{t}$;

$\alpha_{i}, \beta_{i}^{\text {LoC }-w o}, \beta_{i}^{\text {wo }}=$ coefficients unique to share $i$;

$\mathrm{R}_{\mathrm{ux}}{ }^{\text {wo }} \quad=$ the return on the world market index at time $\mathrm{t}$;

$\mathbf{R}_{\max }^{\text {Loc-wo }}=$ the residual local market index return at time $t$, obtained by regressing the returns of the local market index on the world market index returns; and

the following assumptions regarding the $e_{i t}$ are made:

$E\left(e_{i t}\right)=0$

$\operatorname{COV}\left(\mathrm{e}_{\mathrm{ii}} ; \mathrm{e}_{\mathrm{is}}\right)=0 \quad$ for $\mathrm{t} \neq \mathrm{s}$

$\operatorname{COV}\left(R_{m n}{ }^{w 0} ; e_{n}\right)=0 \quad$ for all $t$

$\operatorname{COV}\left(R_{m t}{ }^{L(x: w o ;} ; e_{i t}\right)=0$ for all $t$.

The components of risk for security $i$ can be obtained by considering the expression for the variance of security i's returns:

$$
\begin{aligned}
& \operatorname{Var}\left(R_{i n}\right)=\operatorname{Var}\left(\alpha_{i}+\beta_{i}{ }^{\mu x \cdot w 0} R_{m u^{2(x \cdot} \cdot w 0}+\beta_{i}{ }^{w(1)} R_{m m}^{w 0}+e_{i 1}\right)
\end{aligned}
$$

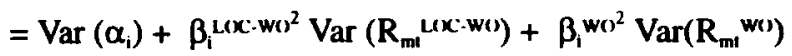

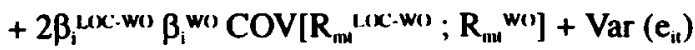

Since $\alpha_{1}$ is a constant $\operatorname{Var}\left(\alpha_{1}\right)=0$ and; by construction $\operatorname{COV}\left[\mathbf{R}_{\mathrm{m}}{ }^{10 \mathrm{C}-\mathrm{wo}} ; \mathbf{R}_{\mathrm{mx}}{ }^{\text {wo }}\right]=0$; the above expression simplifies to:

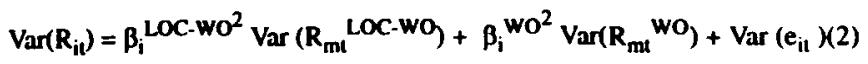

Thus the above expression can be interpreted as: total risk = local market risk only + world market risk + unique (diversifiable) risk.

It is clear that model (1) can easily be extended to include a more comprehensive explanation of an individual shares total risk by including several other specific overseas market indices in the model as well. To obtain tractable expressions for these risk components however, it follows that all independent variables would have to be orthogonal to each other (as was the case for the above model). For the sake of brevity 
Table 2 Percentage of total risk attributable to each these possible extensions will not be formulated here but will be considered further in the ensuing empirical section.

\section{Components of risk: an empirical demonstration}

Copeland \& Weston (1980) state that the market model is not supported by any theory but only assumes that the slope and intercept terms are constant over the time period during which the model is fit to available data. Since the proposed model is similar in spirit to the market model, the focus of the empirical analysis therefore is concerned more with demonstrating the use of the extended model rather than on testing it.

The data used in the empirical demonstration consisted of the monthly ${ }^{2}$ return series of all securities on the JSE with a five-year price history as well as the JSE-Actuaries Overall Index (representing the local market index) and the Morgan Stanley World Index (representing the world market index). The period of study ranged from January 1990 to July 1996.

The multi-market model (1) was estimated using the return data of each of the securities over the period January 1990 to December 1994. ${ }^{3}$

Instead of focussing on the coefficients of the model we focus on the decomposition of total risk into the various components of risk so that the influence of the world market on the risk of local stocks can more easily be examined. Table 2 gives a detailed breakdown of the risk components expressed as a percentage of total risk for all the shares on the JSE which exhibited significant foreign betas over the period January 1990 to December 1994. The shares in Table 2 are ranked according to the percentages of each shares world market risk (relative to total risk).

The risk components derived from Model (1) contain useful information on the risk characteristics of individual securities and as such Table 2 reveals several interesting features.

In particular, after searching across the population of shares on the JSE only 36 securities on the JSE had significant world betas. Furthermore the percentage of world market risk was found to be greater than $10 \%$ for eight of these 36 shares, with Fedsure having the largest component, making up $15.2 \%$ of total risk. The average world risk component was $8.1 \%$.

It can thus be concluded that: the proposed multi-market model is useful, as it provides a way of identifying the proportion of a local shares total risk that is attributable to movements in world markets. We argue that these results may be of particular interest to investors who are restricted by law from fully reaping the benefits of international diversification. Clearly identifying securities with large components of international market risk could be a useful aid for portfolio design. In the final section of this article a portfolio construction technique based on the resulting estimates from running this model is presented and empirically examined and contrasted to some relevant benchmarks.

In the next section we briefly discuss a more sophisticated version of the proposed multi-market model which allows for the consideration of the impact of individual foreign markets on local securities as well.

\section{Extensions for other major markets}

In this section the model is extended to allow for the impact of other specific overseas markets (over and above the impact of the components of risk (as at 31/12/1994) for shares with significant world betas

\begin{tabular}{|c|c|c|c|}
\hline Share name & $\begin{array}{c}\text { World risk }{ }^{\mathbf{a}} \\
\text { Component \% }\end{array}$ & $\begin{array}{c}\text { JSE risk }{ }^{n} \\
\text { Component \% }\end{array}$ & $\begin{array}{l}\text { Unique riskc }^{c} \\
\text { Component } \%\end{array}$ \\
\hline FEDSURE & 15.2 & 8.2 & 76.6 \\
\hline FINTECH & 14.5 & 7.5 & 78.1 \\
\hline INVICTA & 13.8 & 0.7 & 85.5 \\
\hline CHARTER & 13.2 & 1.8 & 85.1 \\
\hline OVBEL & 12.1 & 2.4 & 85.5 \\
\hline PROPFIN & 11.8 & 2.6 & 85.6 \\
\hline JADE & 11.7 & 1.2 & 87.1 \\
\hline W-R-CONS & 10.9 & 4.4 & 84.7 \\
\hline SA-BREWS & 9.5 & 27.1 & 63.4 \\
\hline BERTRAD & 9.4 & 6.1 & 84.5 \\
\hline ALLWEAR & 9.3 & 3.9 & 86.8 \\
\hline BLYVOOR & 9.0 & 6.7 & 84.4 \\
\hline CROOKES & 8.2 & 7.7 & 84.1 \\
\hline MALBAK & 8.2 & 18.8 & 73.0 \\
\hline WALTONS & 7.9 & 26.9 & 65.2 \\
\hline IBJOFFE & 7.8 & 2.4 & 89.8 \\
\hline HYPROP & 7.5 & 4.7 & 87.8 \\
\hline METCASH & 7.5 & 7.8 & 84.7 \\
\hline SPECLTY & 7.3 & 5.2 & 87.5 \\
\hline DA-GAMA & 7.1 & 8.3 & 84.7 \\
\hline BEVCON & 6.9 & 20.6 & 72.5 \\
\hline TAMBOT1 & 6.9 & 1.8 & 91.3 \\
\hline FIT & 6.8 & 9.6 & 83.6 \\
\hline SILTEK & 6.4 & 12.2 & 81.4 \\
\hline LASER & 6.4 & 0.8 & 92.8 \\
\hline PUTCO & 6.2 & 2.4 & 91.4 \\
\hline JASCO & 6.2 & 4.9 & 89.0 \\
\hline CBD-FUND & 6.1 & 1.6 & 92.3 \\
\hline AECI & 5.8 & 11.9 & 82.3 \\
\hline RICHEMONT & 5.7 & 21.9 & 72.3 \\
\hline LEPLAT & 5.2 & 23.4 & 71.4 \\
\hline AMIC & 5.1 & 33.9 & 61.0 \\
\hline WALHOLD & 5.0 & 23.6 & 71.3 \\
\hline SAPPI & 5.0 & 21.0 & 74.1 \\
\hline RUSPLAT & 4.3 & 43.2 & 52.5 \\
\hline ANGLO-AM & 2.1 & 71.4 & 26.5 \\
\hline Average & 8.1 & 12.7 & 79.2 \\
\hline \multicolumn{4}{|c|}{ 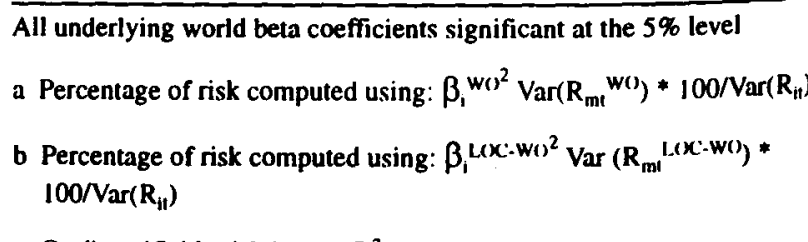 } \\
\hline
\end{tabular}

of the world market) on the risk of local securities. In order to obtain tractable expressions for the resulting risk components, all independent variables are once more orthogonalized. To avoid over elaborate interpretation and estimation procedures, 
the three specific 'other' major markets chosen - the NYSE, the LSE and TSE - are considered separately in the extended models shown below:

$R_{i t}=\alpha_{i}+\beta_{i}^{\text {LOC-WO-USA }} R_{m t}^{\text {LOC-WO-USA }}+\beta_{I}^{\text {USA-WO }} R_{m t}^{\text {USA-WO }}$

$+\beta_{i}{ }^{W O} R_{m t}{ }^{W O}+e_{i t}$

$R_{i t}=\alpha_{i}+\beta_{i}^{\text {LOC-WO-UK }} R_{m t}^{\text {LOC-Wo-UK }}+\beta_{l}^{\text {UK-WO }}$ R $_{m t}^{\text {UK-WO }}+$

$\beta_{i}{ }^{W O} R_{m t}{ }^{W O}+\mathbf{e}_{i t}$

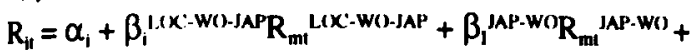

$\beta_{i}{ }^{w 0} R_{m t}{ }^{w 0}+e_{i t}$

where:

$\mathrm{R}_{\mathrm{il}}=$ the return on share $\mathrm{i}$ at time $\mathrm{t}$;

$\alpha_{i}, \beta_{i}^{\text {LXX-WO-USA }}, \beta_{i}^{\text {LCC-W(O-UK }}, \beta_{i}^{\text {L(X-WO-AAP }}, \beta_{i}^{\text {USA-WO }}, \beta_{i}^{\text {UK-WO }}, \beta_{i}^{\text {MAP-WO }}$,

$\beta_{i}{ }^{w 0}=$ coefficients unique to share $i$

$\mathrm{R}_{\mathrm{mt}}{ }^{\mathrm{w0}}=$ the return on the world market index at time $\mathrm{t}$;

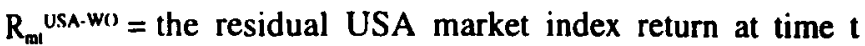

(with the effect of the world return market removed);

$\mathrm{R}_{\mathrm{mI}}^{\mathrm{UK}-\mathrm{w}()}=$ the residual UK market index return at time $\mathrm{t}$ (with the effect of the world market return removed);

$\mathrm{R}_{\mathrm{ml}}{ }^{\text {NAP.Wo }}=$ the residual JAP market index return at time $\mathrm{t}$ (with the effect of the world market return removed);

$R_{\mathrm{mit}}{ }^{L(X-W()-U S A}=$ the residual local market index return at time $t$ (with the effects of both the world and US market returns removed);

$\mathrm{R}_{\mathrm{ml}}^{\text {Loc.w(2) } u K}=$ the residual local market index return at time $t$ (with the effects of both the worid and UK market returns removed);

$\mathrm{R}_{\mathrm{m}}{ }^{\mathrm{LOC}-\mathrm{W}(\mathrm{)}) \mathrm{-AP}}=$ the residual local market index return at time $\mathrm{t}$ (with the effects of both the world and JAP market returns removed)

It can easily be shown that the variance of the dependent variable, $R_{i}$, can be decomposed into several components using either model (3), (4) or (5). From model (3):

$$
\begin{aligned}
& \operatorname{Var}\left(R_{i t}\right)=\beta_{i}^{\text {LOC-WO-USA }}{ }^{2} \operatorname{Var}\left(R_{m t}^{\text {LOC-WO-USA }}\right)+\beta_{i} \text { USA-WO }^{2} \\
& \operatorname{Var}\left(R_{m t}{ }^{\text {USA-WO }}\right)+\beta_{i}{ }^{w \sigma^{2}} \operatorname{Var}\left(R_{n+1}{ }^{W(t)}\right)+\operatorname{Var}\left(e_{i t}\right)
\end{aligned}
$$

which can be interpreted as:

Total risk = local market risk only + USA market risk + world market risk + unique (diversifiable) risk.

Similarly from models (4) and (5) we can decompose the risk into several components.

The regressions (3), (4) and (5) were run on all securities on the JSE with a five-year price history. The resulting beta coefficients are shown in the appendix (Table A3 and A4 respectively).

Table 3 gives a detailed breakdown of the risk components as decomposed in (6) for the period January 1990 to December 1994. Once more these are expressed as a percentage of total risk and the individual shares are ranked according to their percentage of USA market risk.

It is evident from Table 3 that only 66 securities on the JSE has significant USA risk components.

Because South African (and several other restricted LDC) investors are restricted from investing abroad the ability to identify and select individual shares which are significantly related to movements in particular overseas markets based on
Table 3 Percentage of total risk attributable to each of

\begin{tabular}{|c|c|c|c|c|}
\hline Share name & World risk & USA risk & JSE risk ${ }^{c}$ & Unique risk \\
\hline & Component $\%$ & Component $\%$ & Component 9 & Component $\%$ \\
\hline LIB-HOLD & 0.2 & 26.0 & 33.2 & 40.5 \\
\hline CGS-FOOD & 1.4 & 21.8 & 5.7 & 71.2 \\
\hline ALLWEAR & 9.3 & 21.5 & 0.5 & 68.7 \\
\hline RICHEMONT & 5.7 & 20.8 & 12.5 & 61.1 \\
\hline STANPRO & 1.5 & 19.5 & 5.1 & 73.8 \\
\hline LIBERTY & 0.8 & 18.5 & 32.6 & 48.1 \\
\hline ANAMINT & 2.8 & 17.8 & 35.3 & 44.1 \\
\hline CGSMITH & 0.0 & 16.8 & 19.6 & 63.5 \\
\hline DEBEERS & 2.5 & 14.7 & 39.1 & 43.6 \\
\hline LENCO & 0.2 & 13.7 & 13.0 & 73.1 \\
\hline TOCO & 1.0 & 13.5 & 4.9 & 80.6 \\
\hline GRINCOR & 0.2 & 13.4 & 6.8 & 79.6 \\
\hline TEMPORA & 0.3 & 13.2 & 0.7 & 85.8 \\
\hline FR & 2.3 & 13.1 & 0.1 & 84.5 \\
\hline JOHNNIC & 0.3 & 12.4 & 51.4 & 35.8 \\
\hline SUNCRUSH & 5.1 & 12.3 & 2.7 & 79.9 \\
\hline TIB & 0.6 & 12.2 & 39.3 & 47.9 \\
\hline POWTECH & 4.0 & 12.2 & 12.3 & 71.5 \\
\hline CTP & 0.0 & 11.8 & 0.2 & 87.9 \\
\hline REMGRO & 3.7 & 11.7 & 27.1 & 57.5 \\
\hline CBD-FUND & 6.1 & 11.6 & 0.1 & 82.1 \\
\hline CULLINAN & 0.0 & 11.3 & 0.0 & 88.7 \\
\hline REMBR-BEH & 2.2 & 11.1 & 29.6 & 57.1 \\
\hline METPOL & 0.8 & 11.0 & 13.7 & 74.5 \\
\hline MID-WIT & 0.2 & 10.7 & 29.0 & 60.0 \\
\hline TRNSHEX & 3.6 & 10.6 & 0.3 & 85.5 \\
\hline KWV-BEL & 0.0 & 10.5 & 2.6 & 86.9 \\
\hline FOODCRP & 2.7 & 10.5 & 2.9 & 83.9 \\
\hline FIRSTBK & 2.3 & 10.4 & 9.7 & 77.6 \\
\hline INTELES & 0.1 & 10.3 & 11.9 & 77.8 \\
\hline COPI & 0.3 & 10.1 & 4.2 & 85.4 \\
\hline ALTRON & 4.0 & 10.0 & 3.7 & 82.3 \\
\hline AFROX & 0.8 & 9.8 & 12.3 & 77.0 \\
\hline UMDONI & 1.0 & 9.7 & 1.6 & 87.7 \\
\hline METPROP & 3.3 & 9.2 & 1.3 & 86.2 \\
\hline DELTA & 0.6 & 9.0 & 13.5 & 76.9 \\
\hline ELLERINE & 0.2 & 9.0 & 3.6 & 87.2 \\
\hline FEDSURE & 15.2 & 8.9 & 4.4 & 71.5 \\
\hline PALAMIN & 3.3 & 8.6 & 4.5 & 83.6 \\
\hline FRALEX & 0.1 & 8.5 & 5.1 & 86.3 \\
\hline PPC & 3.1 & 8.4 & 7.4 & 81.2 \\
\hline USKO & 0.0 & 8.3 & 5.6 & 86.1 \\
\hline MCPHAIL & 1.1 & 8.0 & 4.8 & 86.2 \\
\hline INHOLD & 0.6 & 8.0 & 9.6 & 81.7 \\
\hline FINTECH & 14.5 & 7.9 & 4.1 & 73.6 \\
\hline TIGR-OATS & 2.3 & 7.8 & 16.3 & 73.6 \\
\hline CHOICE & 3.0 & 7.6 & 0.6 & 88.9 \\
\hline PANPROP & 0.2 & 7.6 & 5.2 & 87.0 \\
\hline
\end{tabular}
the components of risk (as at 31/12/1994) 


\begin{tabular}{lllll} 
NAMPAK & 3.6 & 7.4 & 29.8 & 59.2 \\
GENTYRE-B & 0.3 & 7.3 & 1.7 & 90.7 \\
CENMAG & 0.7 & 7.0 & 3.6 & 88.7 \\
I-G-I & 0.5 & 6.9 & 3.5 & 89.1 \\
DALYS & 4.9 & 6.7 & 0.7 & 87.6 \\
METCASH & 7.5 & 6.6 & 4.6 & 81.3 \\
COASTAL & 0.1 & 6.5 & 1.5 & 91.9 \\
TEGKOR & 0.7 & 6.5 & 18.6 & 74.3 \\
Q-DATA & 0.0 & 6.4 & 1.3 & 92.3 \\
WALHOLD & 5.0 & 6.0 & 18.9 & 70.1 \\
FDCRP-7CP & 1.6 & 5.9 & 3.9 & 88.5 \\
CASHBIL & 0.0 & 5.9 & 5.8 & 88.3 \\
EDGARS & 0. & 5.9 & 4.9 & 88.4 \\
SCHARIG & 3.9 & 5.6 & 11.7 & 78.8 \\
SA-BREWS & 9.5 & 4.5 & 23.0 & 63.0 \\
WALTONS & 7.9 & 4.4 & 23.0 & 64.8 \\
ISCOR & 3.6 & 4.2 & 46.8 & 45.4 \\
ANGLO-AM & 2.1 & 3.5 & 68.2 & 26.2 \\
Average & 2.5 & 10.4 & 12.4 & 74.6 \\
\hline All & & &
\end{tabular}

All underlying USA beta coefficients significant at the $5 \%$ level

a Percentage of risk computed using: $\beta_{1}{ }^{w_{0}{ }^{2}} \operatorname{Var}\left(R_{m t}{ }^{W 0}\right) * 100 / \operatorname{Var}\left(R_{h}\right)$

b Percentage of risk computed using: $\beta_{1}$ USA-WO $^{2} \operatorname{Var}\left(R_{\operatorname{mat}}{ }^{\text {USA-WO }}\right) * 100 /$ $\operatorname{Var}\left(\mathbb{R}_{\mathrm{it}}\right)$

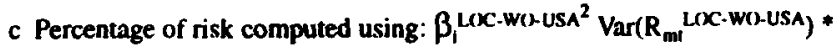
$100 / \operatorname{Var}\left(R_{\mathrm{it}}\right)$

quantitative information is clearly a useful aid to portfolio design. For the case of foreign markets like the USA market, it is clear that only a small proportion of shares on the JSE are related to foreign markets like the NYSE, consequently the quantitative identification of these shares would clearly be of interest to SA investors and portfolio managers alike.

Table 4 and Table 5 show the breakdown of risk components where the other major markets considered are the LSE and the TSE. These risk components (expressed as a percentage of total risk) are computed using an equation similar to (6) and the individual shares are ranked according to their percentage of UK market risk (Table 4) and Japanese market risk (Table 5) respectively.

Once more it is evident from Table 4 and Table 5 that only a small proportion of shares on the JSE are significantly related to movements of the UK and Japanese markets. We argue again that identification of these shares using the above techniques would be of interest to SA (and restricted LDC) investors for portfolio design.

\section{Portfolio design}

In this section we consider the construction of portfolios whose constituents consist of those shares identified as having significant links with overseas markets. The rationale behind such a consideration is that such a fund would, to some extent, mimic the benefits of international diversification (from which South African investors are restricted by regulation). In the preceding section we focussed on identi-

\begin{tabular}{|c|c|c|c|c|}
\hline \multirow[t]{2}{*}{ Share name } & World risk & UK risk ${ }^{n}$ & JSE risk ${ }^{\mathfrak{c}}$ & Unique risk \\
\hline & \multicolumn{4}{|c|}{ Component $\%$ Component $\%$ Component $\%$ Component $\%$} \\
\hline FINTECH & 14.5 & 19.1 & 2.0 & 64.4 \\
\hline BEVCON & 6.9 & 15.6 & 12.0 & 65.4 \\
\hline DEBEERS & 2.5 & 15.5 & 37.9 & 44.0 \\
\hline CGS-FOOD & 1.4 & 14.1 & 6.5 & 78.0 \\
\hline REMBR-BEH & 2.2 & 14.1 & 27.5 & 56.2 \\
\hline ANGLO-AM & 2.1 & 12.4 & 59.8 & 25.7 \\
\hline GENCOR & 3.4 & 12.3 & 27.1 & 57.2 \\
\hline CHARTER & 13.2 & 11.2 & 0.1 & 75.6 \\
\hline RICHEMONT & 5.7 & 10.7 & 14.8 & 68.8 \\
\hline SAMANCOR & 0.7 & 10.5 & 22.6 & 66.2 \\
\hline MAST & 4.0 & 10.3 & 0.2 & 85.6 \\
\hline REMGRO & 3.7 & 9.9 & 27.4 & 59.0 \\
\hline DELTA & 0.6 & 9.9 & 12.7 & 76.8 \\
\hline ANAMINT & 2.8 & 9.7 & 38.9 & 48.7 \\
\hline CTP-6\%-PP & 4.5 & 9.5 & 0.6 & 85.4 \\
\hline TRANS-NTL & 0.1 & 9.3 & 14.2 & 76.4 \\
\hline PREM-GRP & 2.3 & 8.7 & 3.8 & 85.1 \\
\hline CLYDE & 1.4 & 8.7 & 1.1 & 88.7 \\
\hline SA-BREWS & 9.5 & 8.7 & 20.3 & 61.6 \\
\hline A-V-I & 0.6 & 8.1 & 4.0 & 87.3 \\
\hline LIBERTY & 0.8 & 7.9 & 37.5 & 53.8 \\
\hline LASER & 6.4 & 7.7 & 0.0 & 86.0 \\
\hline SAFREN & 0.3 & 7.7 & 7.3 & 84.7 \\
\hline CGSMITH & 0.0 & 7.5 & 23.0 & 69.5 \\
\hline TIB & 0.6 & 7.4 & 42.0 & 50.1 \\
\hline LIB-HOLD & 0.2 & 7.4 & 41.7 & 50.7 \\
\hline BARLOWS & 0.0 & 7.3 & 21.0 & 71.7 \\
\hline CNAGALO & 0.3 & 7.2 & 3.6 & 89.0 \\
\hline AUTOQIP & 0.6 & 6.5 & 2.4 & 90.4 \\
\hline KERSAF & 4.6 & 6.4 & 6.5 & 82.6 \\
\hline RUSPLAT & 4.3 & 6.3 & 37.1 & 52.3 \\
\hline SAPPI & 5.0 & 5.9 & 16.1 & 73.0 \\
\hline CROOKES & 8.2 & 5.7 & 4.5 & 81.6 \\
\hline AMIC & 5.1 & 5.5 & 28.7 & 60.7 \\
\hline TEGKOR & 0.7 & 5.2 & 19.0 & 75.1 \\
\hline NAMPAK & 3.6 & 5.2 & 31.1 & 60.2 \\
\hline JOHNNCC & 0.3 & 4.8 & 57.3 & 37.5 \\
\hline Average & 3.3 & 9.2 & 19.3 & 68.2 \\
\hline
\end{tabular}

All underlying UK beta coefficients significant at the $5 \%$ level

a Percentage of risk computed using: $\beta_{i}^{w()^{2}} \operatorname{Var}\left(R_{m 1}{ }^{w 0}\right) * 100 / \operatorname{Var}\left(R_{i 1}\right)$

b Percentage of risk computed using: $\beta_{1}$ UK-wo ${ }^{2} \operatorname{Var}\left(R_{m l}\right.$ UK-wO $) * 100 /$ $\operatorname{Var}\left(\boldsymbol{R}_{\mathrm{il}}\right)$

c Percentage of risk computed using: $\beta_{1}^{L\left(x \cdot-W()-U K^{2}\right.} \operatorname{Var}\left(R_{m t}{ }^{L(x-W()-U K}\right) *$ $100 / \operatorname{Var}\left(R_{i t}\right)$

fying shares with significant foreign risk components. In this section we examine/assess a portfolio construction technique based on the previous analysis. Portfolios are formed based 


\begin{tabular}{|c|c|c|c|c|}
\hline Share narne & $\begin{array}{c}\text { World risk" } \\
\text { Component } x\end{array}$ & $\begin{array}{c}\text { JAP risk } \\
\text { Component } \%\end{array}$ & $\begin{array}{c}\text { JSE rivkc } \\
\text { Cirnpment } \% \\
\end{array}$ & $\begin{array}{l}\text { Unique rist } \\
\text { Compoment } \$\end{array}$ \\
\hline $\mathrm{ICH}$ & 3.7 & 16.0 & 9.1 & 71.0 \\
\hline PREMPHARM & 3.5 & 13.0 & 0.1 & 83.5 \\
\hline KLOXFF & 0.3 & 11.3 & 27.5 & 60.9 \\
\hline E-DACGA & 1.1 & 11.2 & 14.4 & 73.3 \\
\hline DELCORP & 5.4 & 10.9 & 0.9 & $82 . x$ \\
\hline ALEXWYT & 1.9 & 10.6 & 2.6 & $\times 5.0$ \\
\hline $\mathrm{ACA}$ & 2.4 & 9.8 & 13.1 & 74.7 \\
\hline BOLWEAR & $0 . x$ & 9.4 & 2.2 & 87.7 \\
\hline AIDA & 0.0 & 9.1 & (1.0) & 90.8 \\
\hline TWEEF(NNTN & 0.2 & 9.0 & K.K & $\times 2.0$ \\
\hline REUNERT & 0.0 & 8.9 & 29.9 & 61.2 \\
\hline PORT & 1.9 & 8.9 & 2.5 & *6.7 \\
\hline DUIKERS & 0.0 & $\times .7$ & 10.9 & 80.4 \\
\hline WIT-NIGEL & 0.2 & 8.6 & 0.2 & 91.1 \\
\hline SPANJRD & 0.4 & 8.3 & 1.0 & 90.3 \\
\hline NAMFISH & 0.9 & 7.4 & 0.6 & 91.0 \\
\hline DEELKRL & 0.4 & 7.4 & $1 \times .5$ & 73.7 \\
\hline FIRIM & 4.7 & 7.3 & 3.4 & m.s \\
\hline VOGELS & 0.4 & 7.3 & 16.5 & 75.8 \\
\hline GFSA & 0.3 & 7.3 & 33.3 & 59.2 \\
\hline KETTER & 0.1 & 7.1 & 1.7 & 91.1 \\
\hline BENONI & 1.0 & 7.0 & 2.6 & 89.4 \\
\hline MESSINA & 3.7 & 6.9 & 3.5 & 85.9 \\
\hline GENCOR & 3.4 & 6.9 & 32.7 & 57.1 \\
\hline DA-GAMA & 7.1 & 6.6 & 6.3 & 80.0 \\
\hline INMINS & 2.1 & 6.6 & 2.2 & \$9.1 \\
\hline PROSUURE & 0.0 & 6.5 & $5 . x$ & 87.6 \\
\hline COROHLD & 0.9 & 6.2 & 1.2 & 91.6 \\
\hline HARTIES & 0.2 & 6.2 & 17.1 & 76.5 \\
\hline TECFIN & 0.0 & 6.2 & 0.11 & $93 . x$ \\
\hline TEGKIR & 0.7 & $6.1)$ & 211.6 & 72.7 \\
\hline LORAINE & 0.5 & $6.1)$ & IX.5 & 75.0 \\
\hline NINIAN & 2.4 & 6.0 & 5.9 & x5.7 \\
\hline BENCO) & 1.9 & 5.9 & 11.4 & $\$ 0.7$ \\
\hline FINTECH & 14.5 & 5.8 & 5.7 & 74.0 \\
\hline ZANDPAN & 0.2 & 5.8 & 16.4 & 7.6 \\
\hline E-T-CONS & 0.7 & 5.7 & 17.5 & 76.0 \\
\hline IMPLATS & 2.6 & 5.5 & 32.0 & 59.9 \\
\hline MINORCO & 0.0 & 5.5 & 11.5 & 82.9 \\
\hline ANG-ALPHA & 0.2 & 5.4 & 17.8 & 76.6 \\
\hline DRIES & 3.1 & 5.1 & 29.11 & 62.8 \\
\hline RANDFUNTN & 0.1 & $4 . x$ & 2.3 .4 & 71.7 \\
\hline GENBEL & 2.5 & 4.2 & 43.4 & 49.9 \\
\hline VAAL-REEF & 0.4 & 4.1 & 36.3 & 59.3 \\
\hline LIB-HOLD & 0.2 & 3.7 & 45.4 & 50.3 \\
\hline RUSPLAT & 4.3 & 3.6 & 40.4 & 51.7 \\
\hline KHNNKC & 0.3 & 2.7 & 59.5 & 37.4 \\
\hline Averate & 1.7 & 7.3 & 15.0 & 76.0 \\
\hline
\end{tabular}

All underlying Japancexe hela corefficients significant at the 59 beved

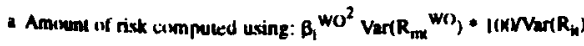

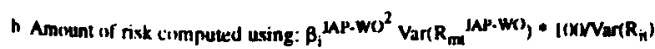

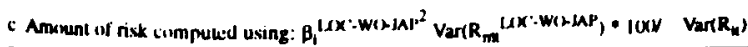

on this identification technique and their performance is examined and contrasted to two South African International unit trusts. ${ }^{4}$
In order to 'set the scene' (for comparison purposes later) we consider the graphical performance of the two longest standing international funds and contrast them to two benchmark indices. Figure 1 depicts the price time series of Standard International Unit Trust, Absa International Unit Trust, the Morgan Stanley World Index in rands and the JSE Actuaries All Share Index. The Morgan Stanley World Index clearly outperforms both the JSE Index and the two international funds. Since these funds can only hold a maximum of $10 \%$ of their assets off-shore, they are composed mainly of shares listed on the JSE. Their performance is therefore more in line with the JSE Index than the MS World Index. It is interesting to note the improved performance of these two funds in early 1996 when the rand fell dramatically. This can be explained by the investment strategy of these funds. It is evident that their constituent holdings comprise a significant weighting of rand-hedge shares on the JSE.

There are two considerations or objectives of international funds:

1. hedging against currency risk; and

2. diversifying into international market action

Examining both the holdings and the performance of these unit trusts it is evident that although the funds are heavily weighted with rand-hedge shares, they do not appear to have a significant component for capturing 'International Diversification'.

Our aim here is to suggest a more quantitative approach to selecting shares which it is hoped will mimic, to some extent, the benefits of international diversification. Our portfolio construction technique involves running the regressions presented in the previous section (Model 1) and identifying shares with significant positive foreign betas. Portfolios are then formed from these shares. The weighting of each share in the portfolio was determined by dividing the shares' foreign beta by the sum of the foreign betas of all the selected shares:

$W_{i}=\beta i / \Sigma \beta_{j}$

where

$W_{i}=$ the weight of share $I$

$\beta_{1}=$ the share's foreign beta

$\Sigma \beta_{1}=$ the sum of the foreign betas of all the selected shares.

In this way, shares with high foreign betas were more heavily weighted in the portfolio.

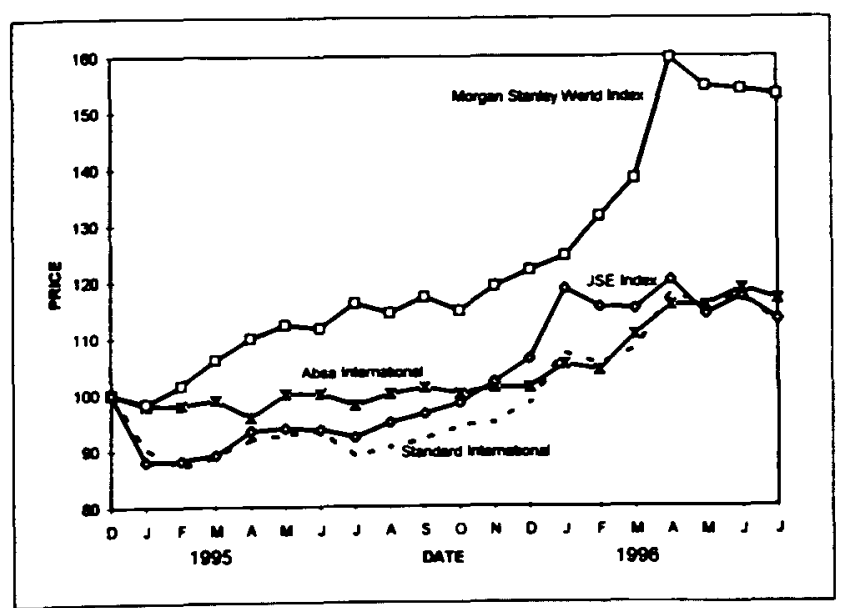

rigure 1 Performance of unit trusts and indices 
Model (1) was run over the period January 1990 to December 1994 and a portfolio was formed using the above construction technique. The performance of this portfolio (henceforth referred to as our 'Global' portfolio) was then tested in the 'unseen' period January 1995 to December 1995. The model was then run again over the period January 1991 to December 1995 and a new portfolio was formed. The performance of this portfolio was then examined over the "unseen' period January 1996 to July 1996. For the sake of simplicity dividends and transaction costs were ignored.

Figure 2 depicts the time series of prices for this portfolio over the test period, January 1995 to July 1996. For comparative purposes the time series of prices for the Morgan Stanley World Index (in rands) and the JSE Actuaries All Share Index are also presented. It is clear that our constructed Global portfolio manages to substantially outperform the JSE Index. It must be kept in mind that all the constituent shares of our 'Global' portfolio are from the JSE. The performance of our portfolio outside the estimation period is more similar to that of the MS World Index than that of the JSE Index.

Figure 3 depicts the prices of the two unit trusts and our 'Global' portfolio. Over the test period our 'Global' portfolio clearly outperforms these two unit trusts. Note that in early 1996 the performance of the two unit trusts improves considerably due to the decline in the rand. Our 'Global' portfolio does not improve over this period.' At this point it is worth

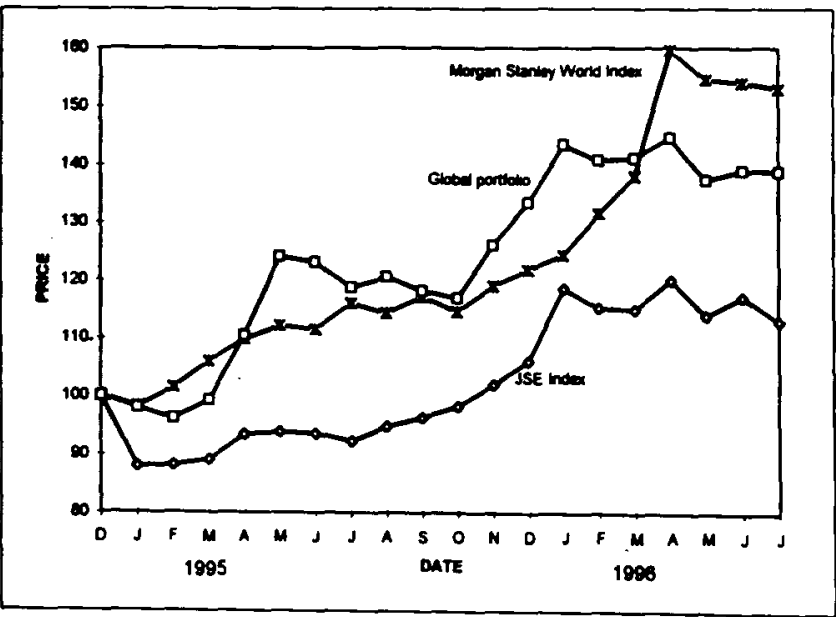

Figure 2 Performance of indices and global portfolio

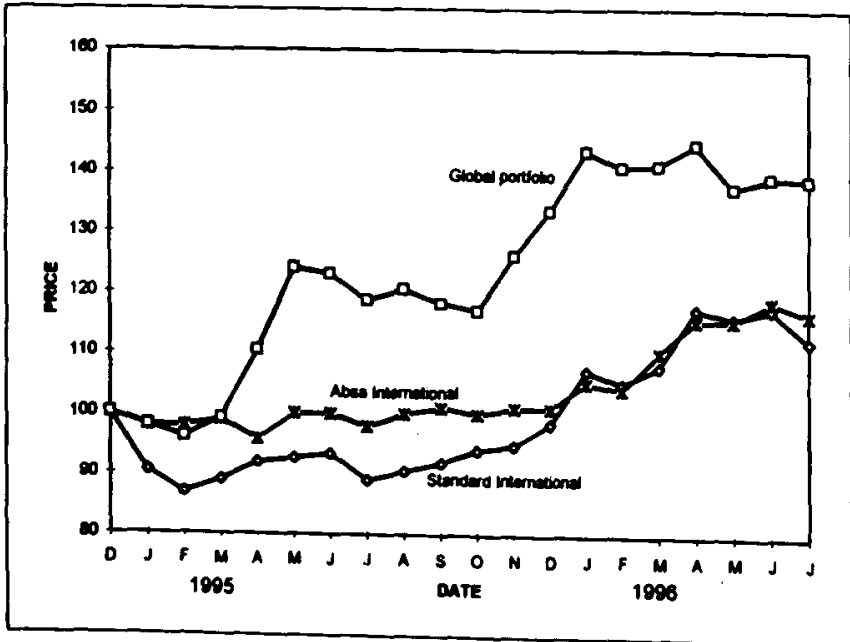

Figure 3 Performance of unit trusts and global portfolio noting that our suggested 'Global portfolio' would obviousty be combined with the maximum allowable funds invested offshore. This off-shore component would clearly have enhanced the performance of the combined portfolio over the above-mentioned period.

The performance of the unit trusts, indices and our 'Global' portfolio are summarized quantitatively in Table 6 and Figure 4.

Table 6 and Figure 4 present summary statistics for our 'Global' portfolio, the two unit trusts and the indices for the period January 1995 to July 1996. The first column is the return over the period. The second column is the standard deviation of the monthly returns over the period and represents the risk of the portfolios. The final column gives a simple risk-adjusted performance measure, the ratio of the return and standard deviation. Clearly our 'Global' portfolio not only has a higher return than the two unit trusts and the JSE Index but also better risk adjusted performance. Although our portfolio underperformed the Morgan Stanley World Index its performance was closer than both the JSE Index and the unit trusts. The risk adjusted performance measure of Absa International fund is fairly close to that of our Global fund. This is, however, largely attributable to the low risk or standard deviation.

\section{Individual country portfolios}

One may also wish to consider portfolios that mimic specific international markets. We therefore ran versions of Model (1) where we replace the Morgan Stanley World Index with the SP500 (NYSE), FT-100 (LSE) and NIKKEI (TSE) to obtain a US Fund, a UK Fund and a Japanese Fund. As with the 'Global' portfolio the funds consist of all shares with significant foreign betas. The weighting of the shares in the funds

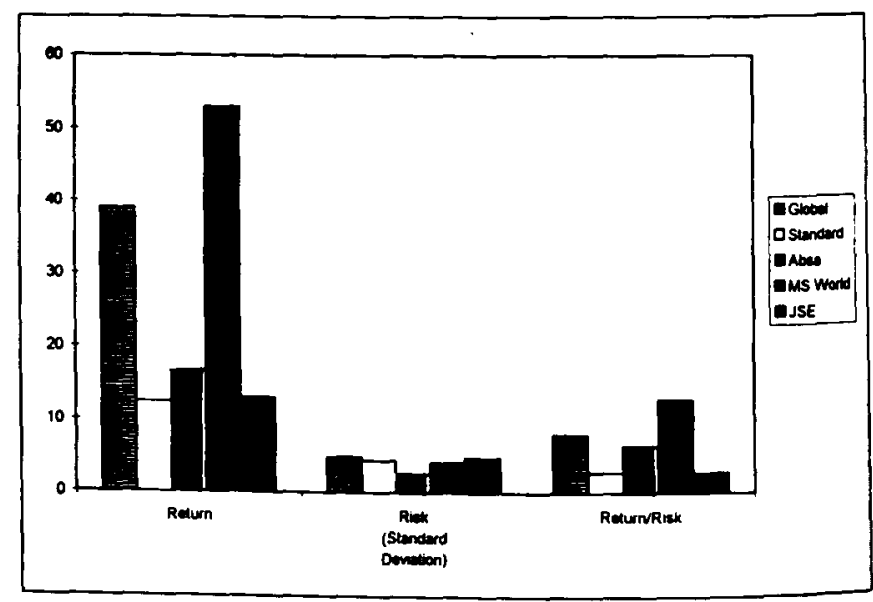

Figure 4 Quantitative performance summary

Table 6 Quantitative performance summary

\begin{tabular}{lccc}
\hline & Return & $\begin{array}{c}\text { Risk (standard } \\
\text { deviation) }\end{array}$ & $\begin{array}{c}\text { Risk adjusted } \\
\text { return }\end{array}$ \\
\hline Global & 39.0 & 4.9 & 8.0 \\
Standard & 12.4 & 4.4 & 2.8 \\
Absa & 16.7 & 2.6 & 6.5 \\
Morgan Stanley & 53.0 & 4.2 & 12.8 \\
JSE & 13.1 & 4.8 & 2.8 \\
\hline
\end{tabular}




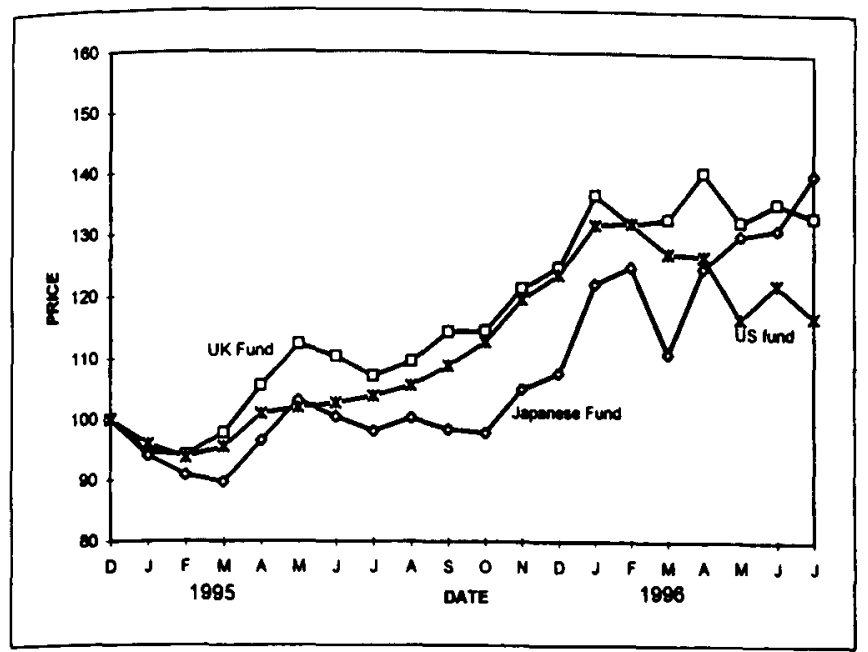

Figure 5 Performance of country funds

is again based on the magnitude of their foreign betas. Figure 5 depicts the performance of these Country Funds over the period January 1995 to July 1996.

It is interesting to note that in the second quarter of 1996 while the US and UK Funds are declining the Japanese Fund performs well. This again highlights the benefits of international diversification. A combined fund was created by selecting all shares with significant foreign betas in the US, UK and Japanese models. If a specific share had a significant foreign beta in more than one model the share's weighting was determined by adding all its foreign betas. Figure 6 depicts the performance of this fund relative to the Morgan Stanley World Index and the JSE Index.

The Combined Fund managed to outperform the JSE Index over the period January 1990 to July 1996 and also avoided the downturn in the JSE Index in the second quarter of 1996. It this way it seemed to mimic, to some extent, the performance of the Morgan Stanley Index.

Figure 7 depicts the performance of the two unit trusts and our Combined fund. Our Combined fund clearly outperforms the two unit trusts. Note that in the last month of the test period, when the price of the JSE Index and both unit trusts declines, the price of the Combined fund remains stable. This can be attributed to the strong positive performance of the Japanese fund over that period.

Table 7 summarizes the performance of the Country Funds and our Combined funds over the period January 1995 to July

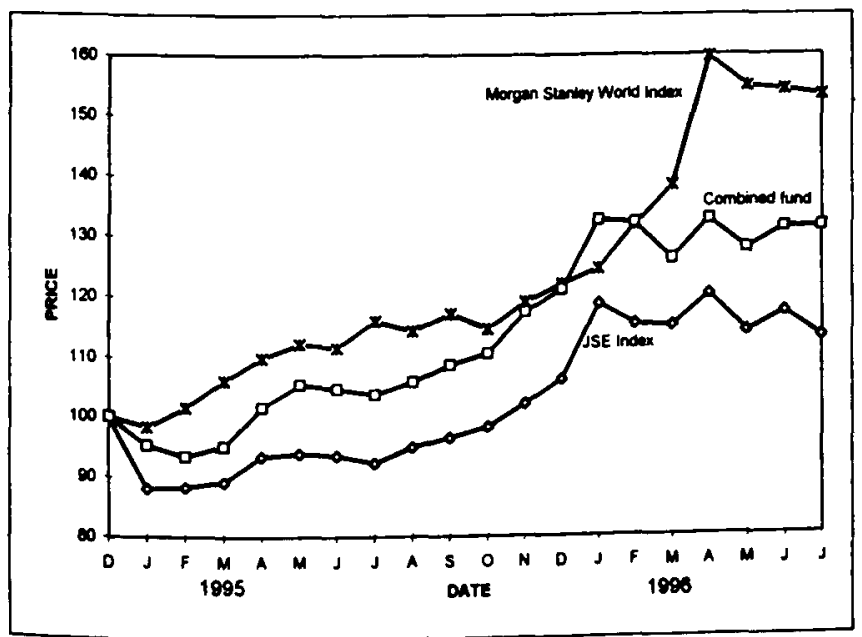

Figure 6 Performance of combined fund and indices

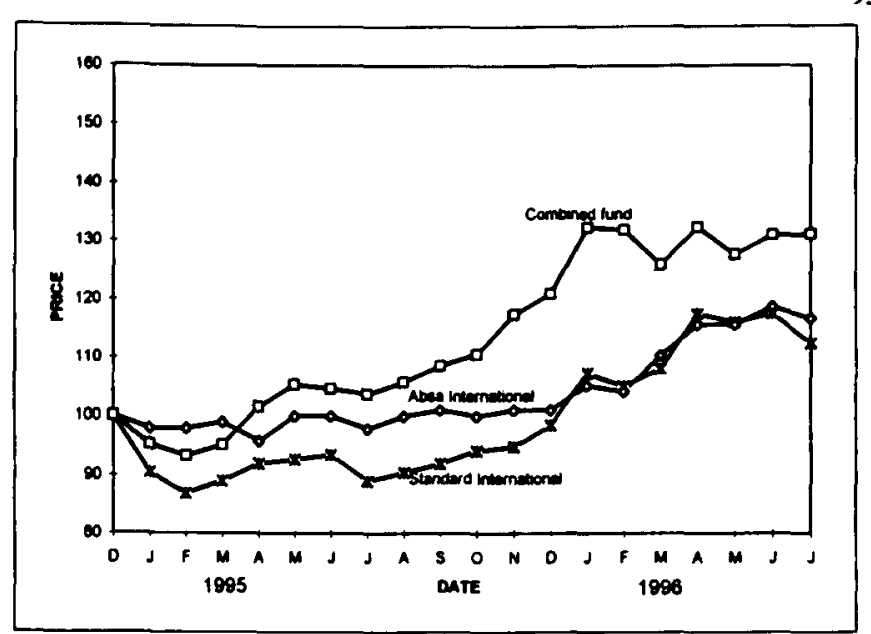

Figure 7 Performance of unit trusts and combined fund

1996. For comparative purposes the performance of the unit trusts and indices are also included.

The return on all of our constructed portfolios is higher than that of both unit trusts. Absa International has a better risk-adjusted performance than the US Fund. As stated before this is largely attributable to the low risk of the Absa International Unit Trust. Furthermore all other constructed portfolios have better risk-adjusted performance than Absa International. All our constructed portfolios outperform Standard International and the JSE Index based on both raw returns and risk-adjusted returns. Apart from the Japanese Index which performed poorly over this period, the world and specific international indices performed notably better than the JSE index. International unit trusts and our constructed portfolios, especially on a risk-adjusted basis. Note, however, that our constructed portfolios came closest to capturing the performance of the Morgan Stanley Index, the New York Stock Exchange and the London Stock Exchange.

\section{Conclusion}

We have demonstrated how local securities with significant foreign risk can be identified using the proposed multi-market model. It is our contention that this information may be of use for portfolio construction. Our empirical demonstration which contrasts the results of our particular portfolio construction methodology with some existing henchmarks gives

\begin{tabular}{lccc}
\hline \multicolumn{4}{l}{ Table 7 Quantitative performance summary } \\
\hline & Return & $\begin{array}{c}\text { Risk (standard } \\
\text { deviation) }\end{array}$ & $\begin{array}{c}\text { Risk adjusted } \\
\text { return }\end{array}$ \\
\hline US Fund & 17.0 & 3.9 & 4.3 \\
UK Fund & 33.3 & 4.4 & 7.5 \\
Japanese Fund & 40.3 & 6.2 & 6.5 \\
Combined Fund & 31.1 & 3.8 & 8.1 \\
Standard & 12.4 & 4.4 & 2.8 \\
Absa & 16.7 & 2.6 & 6.5 \\
Morgan Stanley & 53.0 & 4.2 & 12.8 \\
JSE & 13.1 & 4.8 & 2.8 \\
NYSE & 37.0 & 2.9 & 16.3 \\
LSE & 20.2 & 1.9 & 12.6 \\
TSE & 5.7 & 6.3 & 0.08 \\
\hline
\end{tabular}


support to our contention that portfolios can be enhanced using this knowledge. The portfolio construction technique presented in this article is intended as an aid to portfolio design. We are not advocating rigid adherence to our quantitative selection procedure but rather present it as a tool to enhance portfolio design. There are several variants of the model that could be run to accommodate any tuning or hedging against specific risks, for example rand-hedging. The general form of this model and the use of summarized quantitative information is the essence of what we have attempted to promote in this article.

\section{Notes}

1. The nine LSC's are: Argentina, Brazil, Chile, Greece, India, Korea, Mexico, Thailand and Zimbabwe.

2. Monthly data is traditionally used to estimate the coefficients of the market model.

3. Although the period of study was up until July 1996, the model was fitted for this period in order that there would be some historical 'unseen' data on which to test the effectiveness of the portfolio construction technique in the following section.

4. Absa International and Standard International were the only two unit trusts in existence over the entire test period.

5. Our construction technique, however, was not specifically aimed at creating rand-hedge portfolios but could be fine tuned to hedge against currency risks as well as mimicking international diversification.

\section{References}

Adler, M. \& Dumas, B. 1975. Optimal international acquisitions, Journal of Finance, 30: 1-19.

Adler, M. \& Horesh, R. 1974. The relationship among equity markets: comment, Journal of Finance, 29: 1311-1317.

Agmon, T. 1972. The relationship among equity markets: astudy of share price co-movements in the United States, United Kingdom, Germany and Japan, Journal of Finance, 27: 839-855.

Agmon, T. 1973. The country risk. The significance of the country factor to share price movements in the United Kingdom, Germany and Japan, Journal of Business, 46: 24-32.

Arrow, K.J. 1951. Alternative approaches to the theory of choice in risk-taking situations, Econometrica, 19: 404-437.

Black, F. 1972. Capital market equilibrium with restricted borrowing, Journal of Business, 45: 444-455.

Black, F. 1974. International capital market equilibrium with investment barriers, Journal of Financial Economics, 1: 337-352.

Bradfield, D.J., Affleck-Graves, J.F. \& Barr, G.D.I. 1988. Asset pricing in small markets - the South African case, South African Jour- nal of Business Management, 19: 11-21.

Bradfield, D.J. 1990. The influence of the NYSE on the risk of JSE stocks, De Ratione, 4.

Bradfield, D.J. 1993. Varying market conditions on the NYSE and their effects on non-USA markets, South African Journal of Business Management, 24: 9-44.

Debreu, G. 1959. The theory of value. New York: Wiley and Sons.

Errunza, V. \& Losq, E. 1985. International asset pricing under mild segmentation: theory and test, Journal of Finance, 30(1): 105124.

Errunza, V. 1979. Efficiency and the program to develop capital markets - the Brazilian experience, Journal of Banking and Finance, 3: 355-382.

Fabozzi, F.J. \& Francis, J.C. 1977. Stability tests for alpha's and beta's over Bull and Bear market conditions, Journal of Finance, 32: 1092-1099.

Glenn, D. 1976. Super premium security prices and optimal corporate financing, Journal of Finance, 32: 479-492.

Graver, F.L., Litzenberger, R.H. \& Stehle, R.E. 1976. Sharing rules and equilibrium in an international capital market under uncertainty, Journal of Financial Economics, 3: 233-256.

Lessard, D. 1973. International Portfolio Diversification: A multivariate analysis for a group of Latin American countries, Journal of Finance, 28: 619-633.

Lessard, D.R. 1974. World, national and industry factors in equity returns, Journal of Finance, 9: 379-391.

Levy, R.A. 1974. Beta coefficients as predictors of return, Financial Analysts Journal, 30: 61-69.

Lindahl-Stevens, M. 1980. Redefining Bull and Bear Markets, Financial Analysts Journal, 36: 76-77.

Markowitz, H.M. 1952. Portfolio selection, Journal of Finance, 7: 71-91.

Markowitz, H.M. 1959. Portfolio selection, efficient diversification of investments. New York: Wiley and Sons.

Solnik, B.H. 1974. The international pricing of risk: an empirical investigation of the world market structure, Journal of Finance, 29: 365-378.

Stapleton, R.C. \& Subrahmanyam, M.G. 1974. Market imperfections, capital market equilibrium and corporation finance, Journal of Finance, 32: 307-319.

Stehle, R. 1977. An empirical test of the alternative hypothesis of national and international pricing of risky assets, Journal of Finance, 32: 493-502.

Stulz, R. 1981 a. A model of international asset pricing, Journal of Financial Economics, 9:383-403.

Stulz, R. 1981b. On the effects of barriers to international investment, Journal of Financial Economics, 36: 923-934. 